\title{
Bladder Obstruction
}

National Cancer Institute

\section{Source}

National Cancer Institute. Bladder Obstruction. NCI Thesaurus. Code C79541.

Blockage of the opening between the bladder and the urethra resulting in the reduction or prevention of the urine flow from the bladder into the urethra. 